\title{
LA NARRATIVA BREVE DEL EXILIO DE MARÍA TERESA LEÓN
}

\section{Mª Teresa González de Garay}

Universidad de La Rioja. Gexel-Cefid.

Durante el exilio de María Teresa León vieron la luz los cuentos de Morirás lejos, en Buenos Aires (editorial Americalee) el año de 1942. Allí recuperaba diez relatos publicados en 1936 en México bajo el título de Cuentos de la España actual. Incluía ocho nuevos, y la mezcla de éstos con los anteriores no resultó incoherente porque las preocupaciones sociales y la ideología política eran ya las mismas.

Los diez cuentos nuevos tienen un estilo más elaborado, en el que abundan los rasgos líricos (oníricos en ocasiones), las descripciones de atmósferas y personajes, con una utilización audaz de la creación metafórica que recuerda sus primeras prosas vanguardistas anteriores a la Guerra Civil. Este estilo culto, barroco en ocasiones, siempre muy atento a los detalles de la naturaleza (a la flora y la fauna, especialmente las aves), al vestuario, los perfumes y el mundo interior de los personajes (sobre todo los femeninos y los niños), seguirá acompañando a la escritora en los cuentos que habrá de escribir después, especialmente en sus Fábulas del tiempo amargo.

La colección Morirás lejos hace explícitos problemas sociales del mundo rural y tiene una velada finalidad pedagógica y una posición política comprometida que denuncia la explotación del ser humano.

Los personajes marginales son mayoría, con una insistencia muy pronunciada en los problemas de la infancia miserable, abandonada, huérfana, desheredada y sin horizontes. Muy interesantes en este sentido son los cuentos "Zapatos para el viento", "Luz para los duraznos y las muchachas", "El barco" y "El forastero".

Encontramos la excepción de relatos de corte más autobiográfico que recrean episodios de su infancia o evocan figuras familiares, muy centrados, como es natural, en los sentimientos femeninos (su madre y la "Tata María", por ejemplo, en "El perfume de mi madre era el heliotropo", uno de los mejores de la colección).

O el cuento que da cuerpo a parte de la intrahistoria española con el relato del 
viaje de un soldado pobre, Juan Sedeño, y su yegua Rabona, en el barco que se dirige en 1510 hacia Nueva España, bajo las órdenes de Hernán Cortés, "La hora del caballo". Una yegua que parirá sus potrillos en América, en la nueva tierra para la vida, y que es el espejo del pasado donde pueden mirarse los nuevos transterrados, los exiliados de la España franquista.

El hambre, la ignorancia, la pobreza máximas, más dolorosas por los personajes infantiles que las sufren, se retratan sin paliativos en "Zapatos para el viento" y en "Locos van y vienen", donde hay una mirada grotesca y un tono ácido de farsa que denuncia la actuación de los curas y la iglesia (en un ambiente quizá mexicano).

La opresión de la Guerra Civil española envuelve el grito que profiere la mujer de "Luz para los duraznos y las muchachas": "Nos hacéis hijos para luego matarlos". Desde el mismo título de la colección se apunta al desgarrón que el tema del exilio produjo en los vencidos (veinticinco años más tarde también usó este mismo título el excelente escritor mexicano, José Emilio Pacheco, reciente Premio Cervantes, publicando en Joaquín Mortiz en 1967 una experimental novela sobre la diáspora y el holocausto judíos y sobre la destrucción de Jerusalén por las legiones romanas de Tito). El cuento de María Teresa León, "Morirás lejos", relata la desoladora experiencia de un señor de avanzada edad, coleccionista burgués que vive al margen de la vida política y social y al cual la guerra golpea de lleno, dejándolo tan desorientado y desamparado como a Hamlet García, el metafísico ambulante que da título a la genial novela de otro exiliado, Paulino Masip. ${ }^{1}$ Podemos leer en "Morirás lejos" reflexiones que pertenecen a la instancia narradora, momentos antes de que el coleccionista pierda a su fiel sirvienta y pise tierra extranjera: "Nuestra época está bajo el signo de la huida, del éxodo en bloque; nunca la humanidad semejó más un rebaño calenturiento. Si se retirasen las selvas, si los torrentes se trasladaran buscando lechos más floridos, si las carreteras cansadas de sus trazados intentasen agrandarse, conquistando otras

\footnotetext{
${ }^{1}$ Véase Paulino Masip, El gafe o la necesidad de un responsable, ed. e introducción de $\mathrm{M}^{\mathrm{a}}$ Teresa González de Garay, Biblioteca Riojana, Logroño, 1992.
} 
rutas y terrenos, un clamor de los hombres se levantaría para evitarlo". ${ }^{2}$

La poesía y el estilo de la prosa de María Teresa León convierten estos cuentos en buena literatura, sin restarle fuerza a la denuncia y al claro posicionamiento ideológico. La imagen de la niña que no quiere usar sus primeros zapatos para no mancharlos es inolvidable... ${ }^{3}$

También publica Las peregrinaciones de Teresa durante su exilio en Argentina en 1950, en la colección "La sirena escondida" de ediciones "Botella al mar", dirigida en Buenos Aires por el gallego Arturo Cuadrado, otro exiliado, poeta y editor. Y las Fábulas del tiempo amargo, editadas en 1962 por Alejandro Finisterre en México.

Creemos que las tres colecciones de cuentos del exilio constituyen una magnífica representación de la narrativa española breve de la época. Narrativa que enfoca el mundo femenino, que proyecta una mirada profunda y sabia sobre las situaciones injustas en las que vivieron las mujeres de las primeras décadas del siglo XX tanto en la ciudad como en el mundo rural $-\mathrm{y}$ en el exilio por supuesto-, denunciando y explorando mundos interiores de sentimientos, y su necesidad de libertad, con el espíritu moderno que caracterizó a las valientes escritoras y políticas de la Segunda República española.

En Las peregrinaciones la autora recrea y denuncia la situación que las mujeres tuvieron que soportar en una España muy alejada de la modernidad. Todo ello lo hace a través de personajes llamados simbólicamente con un mismo

\footnotetext{
${ }^{2}$ María Teresa León, “Morirás lejos”, en Una estrella roja, ed. y prólogo de Joaquín Marco, Madrid, Espasa-Calpe, 1979, pp. 97-98.

${ }^{3}$ Dice Joaquín Marco: “Morirás lejos plantea la dialéctica amo-criada, propia del siglo XIX, con características marcadamente burguesas, cuyo ejemplo realista más claro puede ser Misericordia (1897), de Pérez Galdós. Esta mujer de pueblo es una Benina puesta al día. En el relato se introducen también elementos imaginativos, como aquel sueño del coleccionista en el que «ve a su novia con la piel agujereada por la viruela, entrándole y saliéndole pececillos por el cutis a la luz de los arcos voltaicos; su madre, con cara de Basilisa, limpiando el polvo de sus pensamientos; su padre, con la voz del jefe de la defensa pasiva ... ". Pero esta argucia de corte sicoanalítico (no olvidemos la zona oculta irracionalista que aparece también en el reverso de estos relatos) la hallamos ya en la narrativa decimonónica galdosiana. María Teresa León bebe directamente aquí en las fuentes del realismo tradicional español. El perfume de mi madre era el heliotropo constituye una honda y bella investigación en el mundo de la infancia. Es, posiblemente, el mejor relato de los aquí reunidos.
} 
nombre, Teresa, hilo de Ariadna que ayuda a recorrer el laberinto de la soledad y la pérdida definitiva de la libertad y la vida.

En el prólogo María Teresa evoca los días perdidos, su ausencia del tiempo de la España vencedora, los sueños y la memoria más allá, lejos de lo que fue. Los recuerdos atrapan así los sueños que no han podido desaparecer.

El prologuista de los cuentos, González Carbalho, señala aspectos fundamentales del libro, como el valor simbólico del nombre de Teresa (que todas las protagonistas de los cuentos poseen) y la magistral penetración psicológica que se materializa en un estilo lleno de recursos y dominio de la cultura e idioma castellanos. $^{4}$

Dos cuentos enmarcan la colección: el primero se titula "Cabeza de ajo" y el último "Esplendor de Teresa". En ambos la Guerra civil gravita como la circunstancia histórica traumática que modifica la vida de la colectividad, pero en los cuentos la autora enfoca especialmente las consecuencias de la misma para dos clases de mujeres muy diferentes: una mujer madura que conserva algo de belleza, virgen a su pesar y dependiente de una madre autoritaria, observadora y minuciosa; una mujer urbana y medrosa, inútil y ociosa, frente a la mujer rural de "Esplendor de Teresa", ignorante pero sabia, elemental aunque llena de matices, enamorada sin palabras de un marido que se esconde en las montañas (símbolo y paradigma de los maquis).

En el primero se retrata la mezcla de sexo y muerte, eros y tánatos. En el último aparece el amor, un amor estremecedor y redentor, sublime en su contraste con la crueldad de los verdugos.

En el primero, "Cabeza de ajo", escuchamos la voz de la narradora omnisciente, identificada con la autora (recordemos que ella contó en sus memorias cómo su propia madre, con la que mantuvo a veces los naturales conflictos, le llamaba así en su niñez). María Teresa crea sus cuentos desde el recuerdo de experiencias y observaciones de la España anterior al éxodo. $Y$ a veces esas experiencias han sido vividas en primera persona en alguno de sus episodios, nutriendo matices y

\footnotetext{
${ }^{4}$ María Teresa León, Las peregrinaciones de Teresa, ed. cit., pp. 7-8.
} 
detalles del carácter de los personajes inventados que, por supuesto, no se corresponden con la vida personal de la autora, aunque contribuyen a dotar a sus relatos de emoción, empatía, sinceridad y verosimilitud. ${ }^{5}$

En el retrato sintético de ambos personajes femeninos destaca la eficacia del estilo de María Teresa León para expresar el contraste entre madre e hija. Dos cuerpos, dos modos de moverse, diferentes sueños y esperanzas unidos en una relación asfixiante que se desarrolla en la casa vetusta y estrecha de un Madrid atemorizado y sórdido, con la guerra civil envolviendo constante los actos de la vida cotidiana. ${ }^{6}$

Después la narradora cede la voz a la protagonista para hacernos conocer sus sueños más íntimos, sus frustraciones, su deseo sexual reprimido, su religiosidad de santos y novenas y su pseudoideología de pequeña burguesa quintacolumnista, antirrepublicana y partidaria del ejército rebelde, sin saber muy bien qué significa todo ello, poco consciente, alienada en fin, como perfectamente una solterona ignorante de aquella época podía estarlo. ${ }^{7}$

En el monólogo interior vemos reflejado el mundo de esta primera Teresa, en el que aún no ha aparecido ni una brizna de libertad, ni un estremecimiento de placer. “Teresa está sola. En cada esquina de sí, la resonancia de sus sueños". ${ }^{8}$ Y en esa soledad aparece el soldado republicano herido, enemigo por tanto, con el que perderá su virginidad polvorienta, unos instantes antes de que éste muera. El encuentro demuestra la capacidad dramática de María Teresa León porque se ofrece a través del diálogo entre los dos personajes, con pequeños apuntes de la narradora, líricos, descriptivos o psicológicos. ${ }^{9}$

En el momento final del relato nos damos cuenta de que los miedos de la hija no eran compartidos en absoluto por una madre que, con su respuesta brusca y cruel, se aleja ideológica y vitalmente de la hija en un movimiento paradójico. Una incomprensión más añadida al mundo femenino. Madre e hija, unidas en todos los

${ }^{5}$ María Teresa León, Fábulas del tiempo amargo y otros relatos, edición e introducción de Gregorio Torres Nebrera, Madrid, Cátedra, 2003, p. 262.

${ }^{6}$ Ibid., p. 262.

${ }^{7}$ Ibid., pp. 262-63.

${ }^{8}$ Ibid., p. 263.

${ }^{9}$ Ibid., pp. 263-64. 
actos de la vida cotidiana y alejadas por un abismo de desconocimiento e incomunicación. Teresa más sola que nunca con la muerte de lo más deseado entre los brazos.

La terrible experiencia que inunda a la Teresa que inicia la colección no sabemos en qué desembocará, ni qué será de su vida en adelante porque el cuento termina abruptamente, aunque pueda conjeturarse una reacción no muy feliz. Sí sabemos, sin embargo, cómo acabará la vida para la última Teresa del libro, la de "Esplendor de Teresa". La escena tragicómica del primer cuento se convierte en una auténtica tragedia heroica en el último. Allí la muerte y el amor están reunidos en un abrazo desesperado y dolorido pero absolutamente consciente de lo que significa su sacrificio: la vida para los que aún luchan en el monte contra los opresores y la dignidad del pueblo inocente. La unión en la muerte, en el quebrantamiento y dolor de las torturas, se dulcifica por el amor. Lucas ha ido a salvar la vida de Teresa, a cambio de la suya, porque la ama profundamente con todo su ser.

El cuento está situado en la inmediata posguerra. Bandas de fascistas represores recorren una pequeña y aislada aldea en busca de venganza, poder y botín. Sus acciones terribles, asesinando a una valiente vecina, poco sumisa, de manera inhumana ante todo el pueblo, desencadena la respuesta indignada de los hombres del pueblo que fusilan al asesino y después huyen al monte. Teresa ayuda a su marido, un humilde y sencillo pastor, dándole el fusil con el que harán justicia y apoyando su fuga. Cuando otro grupo de fascistas retorna al pueblo a dar el escarmiento, lo primero que hacen es tomar a Teresa como prisionera y rehén para obligar a su marido a salir del monte y a entregarse a los vencedores que les buscan. El trato es el de la vida de Lucas por la de Teresa. Las torturas y la atmósfera son narradas de manera magistral, con un realismo impresionista, y también con rasgos expresionistas, sin concesiones.

Además el sacrificio de Teresa es paradigmático porque ella representa un tipo de mujer ancestral, arquetípica, que parece insignificante en el mundo social y privado de la aldea, pero no lo es en absoluto porque encierra valores nobles y elevados a pesar de su falta de mundo y cultura urbana. 
Otras siete Teresas protagonistas pueblan estos cuentos. La niña perdida en el bosque ("Me extravié en el bosque al querer ser yo" dice con lucidez, en "El noviciado de Teresa", el quinto, uno de los mejores, según Gregorio Torres Nebrera), eje central y organizador de la estructura completa del libro, con ricas y variadas evocaciones históricas del territorio castellano y del Burgos de su niñez, adolescencia y primera juventud, referencias al mundo infantil de los cuentos maravillosos, descripciones y evocaciones del bosque llenas de sensibilidad y lirismo.

Y, sobre todo, el osado y rebelde peregrinaje femenino en busca de la libertad personal, que nos habla también de clases sociales y del deseo de independencia con una originalidad y eficacias muy notables: "Teresa tenía todo el temblor de lo que falta. [...] La sed huyó ante el miedo, el deseo de independencia ante la necesidad de protección". ${ }^{10}$ En el cuento lo fantástico envuelve con su misterio problemas tan reales como la construcción de la propia identidad, rompiendo con las normas impuestas y con la vieja Teresa (¿espejo de su propia biografía?) y la elección definitiva, aunque forzada por las religiosas y por San Amaro, de un nuevo proyecto de vida, al lado de los pobres. Ante la disyuntiva que se le ofrece de quedarse en el convento de las Huelgas Reales, que exigen prosapia aristocrática, o con la orden franciscana mendicante, consagrada a leprosos y caminantes, opta por la última. "Como en los cuentos castellanos de La bella del mal amor, se advierte también en este relato -escribe Nebrera - un cierto matiz social: aristocratismo excluyente y discriminador frente a populismo solidario". ${ }^{11}$

Pero el cuento acaba — sazonado con un tono de humor irónico y amargocon la advertencia de la narradora: "Niñas, cuando os extraviéis en un bosque, cuidado de no tropezaros con un santo". ${ }^{12}$ Otra toma de conciencia y otro compromiso inequívocos de la escritora.

El cuento de "La tía Teresa" narra la triste desventura de la tía emigrada y fracasada. Del rechazo que la familia le muestra cuando ve que ésta no cumplió con los sueños de riqueza que todos esperaban. Una desterrada que sigue

\footnotetext{
${ }^{10}$ María Teresa León, Las peregrinaciones de Teresa, Buenos Aires, 1950, pp. 62 a 65.

${ }^{11}$ Torres Nebrera, ed. cit., 2003, p. 81.

${ }^{12}$ Las peregrinaciones de Teresa, ed. cit., 1950, p. 77.
} 
siéndolo al regresar, excluida doblemente y para siempre de la integración social. Vieja, sola, pobre y sin rastro de su antigua belleza. El desmoronamiento de un mito muy arraigado, pero sin fundamento. Una mujer osada y rebelde que incumple con las expectativas de triunfo social.

"El diluvio de Teresa", uno de los más cómicos y más literarios, con resonancias de la historia "del mancebo que casó con mujer brava" de El Conde Lucanor de Don Juan Manuel, también lleno de elementos anticlericales, puestos de manifiesto en el abuso al que el cura del lugar somete a una mujer a la que cree indefensa y de la que espera conseguir riquezas y beneficios con el engaño y la trampa. Esta Teresa no sólo no se deja amilanar sino que saca provecho del lance.

Tenemos que mencionar, al menos, a la Teresa de la "Primera peregrinación de Teresa", también niña y llena de fantasías y salud. En relación constante con huérfanas, excluidas, minusválidas, monjas (convencionales e infractora) y un pequeño príncipe azul, representado en el jovencito jardinero del convento. Esta Teresa, sin duda, crece al enfrentarse a una experiencia de aprendizaje, a la pérdida de la inocencia, y también a la soledad.

La Teresa de "Tres pies al galgo", una historia en la tradición de la malmaridada, se empareja temáticamente con la que protagoniza otra Teresa en "Los otros cuarenta años". La primera no ha podido consumar el matrimonio con su esposo, un profesor mayor que ella, desinteresado por completo del sexo, y vive con gran frustración una maternidad imposible. La otra es una mujer abandonada por su marido, sin palabras, tras 40 años de matrimonio. El marido abandona a su mujer por otra más joven dejando a ésta, en medio de un río en el que trata de reconstruir su pasado, con la vida rota. Este cuento posee sobresalientes calidades de estilo: poético y filosófico.

Finalmente hay otra Teresa, alter ego de la autora, que será la narradora de la historia de "Madame Pimentón", una mujer también fracasada y medio loca, excluida de la sociedad, atrabiliaria, rara, excéntrica, pero libre aún, como lo fue en su juventud de belleza y triunfos en París, cuando aún se llamaba Teresa y bailaba llena de gracia y libertad.

Se hace evidente que María Teresa León peregrina con sus Teresas por los 
territorios de la patria físicamente perdida, pero siempre presente en su imaginario literario y en sus sentimientos de cultivada escritora española.

Joaquín Marco indica en el estudio introductorio a su antología Una estrella roja (en la que incluye las colecciones de relatos Cuentos de la España actual, Morirás lejos y Fábulas del tiempo amargo, pero no Las peregrinaciones de Teresa) la importancia de la narrativa de María Teresa León en la prosa de la generación del 27, por la nueva perspectiva femenina que su literatura adopta y por su aire renovador, el de "una mujer que es, a la vez, una militante revolucionaria". ${ }^{13}$

Para completar la contextualización de estas Peregrinaciones, mencionaremos las últimas narraciones breves escritas por María Teresa en su exilio argentino, tituladas Fábulas del tiempo amargo. La "fábula" es una manera de organizar los contenidos literarios que potencia la fuerza de la alegoría, los arquetipos y los símbolos. $Y$ es un cauce que nuestra autora domina con especial virtuosismo, exacerbando los registros simbólicos, expresionistas e impresionistas.

Además hay que sumar el hecho de que estos relatos cultivan una lengua castellana flexible y enriquecida, heredera de una larga tradición literaria y retórica, la de las historias de las literaturas hispánicas y europeas y la de las literaturas clásicas, desde los poemas homéricos, pasando por los textos medievales y los del Siglo de Oro, hasta llegar a las vanguardias artísticas de entreguerras y a los postulados del realismo socialista y de la literatura comprometida. Todo ello lo conoce perfectamente y nutre a nuestra escritora.

Sus cinco Fábulas del tiempo amargo son imposibles de concebir sin la Guerra Civil y el exilio.

Todas son interesantes. La primera "Soledad ¿por quién preguntas?" es un relato onírico que recrea el imposible rito de iniciación de la protagonista en el seno de una tribu extraña y lejana. Ella se ha desplazado (el exilio se hace presente de modo simbólico), está desnuda y no puede más que tejer para ser aceptada. El simbolismo es ritual y funerario.

\footnotetext{
${ }^{13}$ Una estrella roja, ed. cit., p. 18.
} 
La segunda "Comed, comed, que ya estoy invitada" vuelve a tener una textura de pesadilla macabra, surrealista y alegórica. Identificada con la "corza" vencida, una muchedumbre, tras la montería, se prepara para el festín de comérsela en un castillo inconexo. Entre los comensales está su madre y se alude a otros familiares... Todos desdeñan su cabeza, que está en la fuente, mientras su sangre quedó en la cocina... Nadie la ve, pero la oyen, aunque no entienden lo importante, nada saben de ella. El final proclama la rebeldía y la reacción de la escritora. Les grita que esa cabeza es ella y concluye: "agarro mi cabeza y desaparezco del salón del banquete sin dar a nadie cuenta de mis actos". ${ }^{14}$ La ruptura con el viejo mundo clasista, burgués e insolidario está consumada. Y la huida de un sacrificio inútil.

La tercera, titulada "El viaje", recrea magistralmente, desde una perspectiva mítico-poética, con tonos épicos de derrota, el exilio de España hacia Orán, tras la derrota y fin de la Guerra Civil, en una avioneta roja junto a Alberti y otras cuatro personas. En esta Fábula nos encontramos con un onírico vuelo de la narradora sobre un águila, tras una conversación con el Zorro y el Lobo, no referida, sino nombrada como pesadilla. Animales emblemáticos que siempre han acompañado al hombre en su imaginario literario. Montada en el Águila la protagonista y narradora contempla por última vez los campos de Levante, el mar, otro continente. El dolor por los que no pueden escapar, por la pérdida de todo lo querido, la patria que es tierra, geografía, amigos, amores, ideales, vivencias y recuerdos, conduce a la narradora a visiones intensas cargadas de desesperanza, temor e incertidumbre.

En Memoria de la Melancolía evoca el aterrizaje forzoso en tierras argelinas y cómo las autoridades le quitaron la pistola que llevaba en la cintura ("la entregué (...) mordiéndome los labios"). La lucha había acabado. Y los mejores años de energía y juventud socializados. Y los sueños de un mundo mejor. Comenzaba el exilio.

Que es el tema que va a desarrollar en las dos fábulas siguientes, "Las estatuas" y "Por aquí, por allá".

En "Las estatuas" todas las actitudes frente al exilio son consignadas (la de los que se acomodan y buscan su único interés y la de los leales a sus ideas

\footnotetext{
${ }^{14}$ Ibid., p. 314.
} 
universales de justicia, libertad y fraternidad; la de quienes emprenden con valor el nuevo reto y la de los cobardes que quieren regresar sometiéndose; la de los que hablan y protestan y la de los que los silencian). El exilio mostró la verdadera cara de hombres y mujeres. Y los infinitos obstáculos con que los refugiados se encontraron quedan simbolizados por las estatuas y los hombrecitos de papel, burócratas al servicio de un poder abstracto, funcionarios crueles, personas deshumanizadas que no comprenden el drama de los miles de desplazados que llegan —naúfragos - a los países extranjeros. Estas estatuas de María Teresa no tienen nada que ver con las estatuas que hacían ante el tren las niñas de Julio Cortázar en "Final de juego". Las estatuas de León son figuras opresoras y desprovistas de cualquier belleza e idealismo. Son los esclavos de los poderosos y de los verdugos.

En la última Fábula, "Por aquí, por allá", se condensan muchos de los elementos claves de la obra literaria de María Teresa León: la infancia y juventud de la escritora, la guerra civil, el exilio, la desesperanza por el presente y el futuro de España, el problemático regreso, su viejo barrio madrileño, los antiguos mitos encarnados en Ulises, la libertad del lenguaje aprendida en sus contactos con las vanguardias y con el mejor surrealismo (el español de Picasso y el de Buñuel, el creacionismo de Huidobro, el ultraísmo...), y también la confianza en una vida que continúa a pesar de todo, venciendo el dolor con la dignidad y la fidelidad a uno mismo. La fábula se estructura con un marco simétrico (el comienzo y el final son idénticos) que envuelve en un velo de magia y misterio la voz, en primera persona, de la narración: "En la falda del viento recliné la cabeza y concluyó mi sueño". ${ }^{15} \mathrm{La}$ narradora parece dejarse flotar, como una hoja otoñal desprendida de los árboles, ya aceptada su errancia, superadas las pruebas, liberada de la lógica de lo real verificable, entregada a la reflexión más desprotegida, al pensamiento más amargo, pero también al lenguaje de la autoafirmación y lealtad a sus valores, al lenguaje de la poesía y de la esperanza.

Los cuentos del exilio de María Teresa León se merecen una atenta lectura y una primera edición española —en condiciones- que esperamos y deseamos que

${ }^{15}$ María Teresa León, Fábulas del tiempo amargo y otros relatos, ed. cit. de Gregorio Torres Nebrera, pp. 331-343. 
esté a punto de ver la luz en el próximo año de 2009, setenta años después del doloroso exilio de los republicanos españoles tras su derrota en la Guerra Civil española de 1936.

\section{BIBLIOGRAFÍA}

\section{OBRA LITERARIA DE MARÍA TERESA LEÓN EN EL EXILIO}

Contra viento y marea, Buenos Aires, Ediciones Aiape, 1941, 329 páginas. Prólogo de la autora, páginas 7-8.

Morirás lejos, Buenos Aires, Editorial Americalee, 1942, 219 páginas.

—. Una estrella roja, Madrid, Espasa-Calpe, colección Austral, 1979, 192 páginas. Prólogo de Joaquín Marco, páginas 9-23. En esta obra se seleccionan los relatos de Cuentos de la España actual, Morirás lejos y Fábulas del tiempo amargo.

La historia tiene la palabra (Noticia sobre el Salvamento del Tesoro Artístico), Buenos Aires, Patronato Hispano-Argentino de cultura, 1944.

—- Madrid, Hispamerca, 1977, 123 páginas, prólogo, selección del apéndice y notas de Gonzalo Santonja.

El gran amor de Gustavo Adolfo Bécquer, (Una vida pobre y apasionada), con las Rimas del poeta, poema y epílogo de Rafael Alberti, Buenos Aires, Editorial Losada, colección Biografías Históricas y novelescas, 1946 (1951), 162 páginas.

Las peregrinaciones de Teresa, Buenos Aires, Ediciones Botella al mar, colección La Sirena Escondida, 1950, 123 páginas. Prólogo de González Carbalho, páginas 7-8.

Don Rodrigo Díaz de Vivar, El Cid Campeador, Buenos Aires, Peuser, 4, 174 páginas.

, Buenos Aires, Compañía General Fabril editora, colección Los Libros del Mirasol, 1962 (1968, 1972, 1976, 1978, 1979, 1982, 1984, 1986), 126 páginas; Burgos, Editorial Gran Vía, prólogo de Benjamín 
Prado, (pp. III-VIII), preliminar de Juan Carlos Estébanez Gil (pp. IXXXIX), 2007, 183 páginas.

Nuestro hogar de cada día. Breviario para la mujer de su casa, Buenos Aires, Compañía General Fabril Editora, 1958 (1959, 1961), 305 páginas.

Sonríe China, Buenos Aires, Editor Jacobo Muchnik, 1958, 229 páginas. Con los Poemas de Rafael Alberti del libro de análogo título e ilustraciones en colores de Rafael Alberti.

Juego Limpio, Buenos Aires, Editorial Goyanarte, colección El mundo al día, 1959, 264 páginas.

, Barcelona, Seix Barral, 1987, 290 páginas; Madrid, Visor librosConsejería de Educación de la Comunidad de Madrid, colección Letras Madrileñas Contemporáneas, 2000, con prólogo de Luis García Montero).

Doña Jimena Díaz de Vivar, gran señora de todos los deberes, Buenos Aires, Losada, Biblioteca Contemporánea, 1960, 176 páginas.

, Madrid, Biblioteca Nueva, 1968, 212 páginas; Barcelona, Círculo de Lectores, 1993, 221 páginas, con prólogo de José-Carlos Mainer; Burgos, Instituto Municipal de Cultura, 1999, 254 páginas, con introducción de Juan Carlos Estébanez Gil, páginas 7-43; Madrid, editorial Castalia, edición, introducción y glosario de Margarita Smerdou Altolaguirre, páginas 8-32, Biblioteca de escritoras, 2004, 229 páginas.

Fábulas del tiempo amargo, Méjico, Ecuador 00'0" Revista de Poesía Universal, octubre de 1962, 60 páginas.

Fábulas del tiempo amargo y otros relatos, Madrid, Cátedra, Letras Hispánicas, edición, prólogo y notas de Gregorio Torres Nebrera (pp. 11 102), 2003, páginas 305-343.

, Una estrella roja, Madrid, Espasa-Calpe, colección Austral, 1979, 192 páginas. Prólogo de Joaquín Marco, páginas 9-23. En esta obra se seleccionan los relatos de Fábulas del tiempo amargo. 
Menesteos, marinero de abril, Méjico, Editorial Era, 1965, 124 páginas.

, Barcelona, Seix-Barral, Biblioteca Breve de Bolsillo, 1972, 130 páginas.

Cervantes, Buenos Aires, Centro Editor de América Latina, 1969.

Memoria de la Melancolía, Buenos Aires, Losada, colección "Cristal del tiempo", 1970, 331 páginas.

, Barcelona, Editorial Laia/Ediciones Picaza, 1977, 356 páginas; Barcelona, Bruguera 1979 (1982), 382 páginas; Barcelona, Círculo de Lectores, 1979 (1987), 334 páginas (la edición de 1987, con prólogo de Rafael Alberti, páginas I-V, y epílogo de María Asunción Mateo, páginas 289-293), con ilustraciones de Rafael Alberti; Madrid, Castalia, Clásicos Castalia, 1998, 545 páginas. Introducción y notas de Gregorio Torres Nebrera, pp. 7-65; Barcelona, Galaxia Gutenberg, 1999; La Habana, Casa Editora Abril, 2001, colección Sur, con epílogo de Lina de Feria (pp. 345349), 365 páginas.

Cervantes, el soldado que nos enseñó a hablar, Madrid, Altalena editores, colección Mundo ancho y propio, 1978, 196 páginas. Ilustraciones de Carlos Alonso y Oscar Mara.

Alcalá de Henares, Universidad de Alcalá de Henares, 2004; La Habana, editorial Gente Nueva, 2005, epílogo de Fina García Marruz (pp. 179-208), notas de Esteban Llorach (pp. 209-267), ilustraciones de José Luis Fariñas, 267 páginas; Pamplona, Liber ediciones, 2007, edición de bibliófilo ilustrada por José Luis Fariñas, prólogo de Almudena Grandes. (Existe edición facsimilar).

Una estrella roja, Madrid, Espasa-Calpe, colección Austral, 1979, 192 páginas. Prólogo de Joaquín Marco, páginas 9-23. En esta obra se seleccionan los relatos de Cuentos de la España actual, Morirás lejos y Fábulas del tiempo amargo. 
La libertad en el tejado, Revista Encuentros, San Cugat del Vallés, no 9-10 (1989), ed. de Manuel Aznar Soler. Encarte de 36 páginas.

, Barcelona, Associació d' Idees Gexel, colección Winnipeg, 1995, 127 páginas, con prólogo de Salvador Arias, páginas 5-6. Edición e introducción de Manuel Aznar Soler, páginas 7-35. En Apéndice se recogen los artículos sobre teatro soviético que publicó María Teresa León en El Heraldo de Madrid, entre el 20 de mayo y el 21 de agosto de 1933; Sevilla, Renacimiento, colección Biblioteca del exilio, 2003, 405 páginas, en María Teresa León, Teatro. La libertad en el tejado. Sueño y verdad de Francisco de Goya, edición, estudio y notas de Manuel Aznar Soler.

Sueño y verdad de Francisco de Goya, Sevilla, Renacimiento, colección Biblioteca del exilio, 2003, 405 página, incluida en María Teresa León, Teatro. La libertad en el tejado. Sueño y verdad de Francisco de Goya, edición, estudio y notas de Manuel Aznar Soler.

Misericordia, Madrid, Asociación de Directores de Escena, 2003, incluida en María Teresa León, Teatro. Escritos sobre teatro, edición, prólogo y notas de Gregorio Torres Nebrera.

La madre infatigable, (Guión radiofónico), Edición de Sagrario Ruiz Baños, Ínsula, 557 (mayo de 1993), páginas 16-19.

, Madrid, Asociación de Directores de Escena, en María Teresa León, Teatro. Escritos sobre teatro, 2003, páginas 273-291.

La historia de mi madre, (Guión radiofónico), Pliegos de la Academia, El Puerto de Santa María, 17 (octubre de 1995), páginas 10-13.

, Madrid, Asociación de Directores de Escena, en María Teresa León, Teatro. Escritos sobre teatro, 2003, páginas 292-305. 
La historia de mi corazón (teatro), edición facsimilar y transcrita, y prólogo de Gabriele Morelli, pp. 11-23, Málaga, Centro Cultural Generación del 27, 2009.

\section{BIBLIOGRAFÍA SOBRE MARÍA TERESA LEÓN}

AA.VV., María Teresa León, Valladolid, Consejería de Educación y Cultura de la Junta de Castilla y León, 1987.

AA VV., Homenaje a María Teresa León, Madrid, Universidad Complutense de Madrid, Cursos de Verano de El Escorial, 1990.

AA.VV., María Teresa León, 1903-1988, Madrid, Concejalía de juventud del Ayuntamiento de Madrid, 1990.

AA.VV., Sesenta años después. El exilio literario de 1939, ed. de María Teresa González de Garay y Juan Aguilera, Tomo VIII, Logroño, Universidad de la Rioja, Gexel, 2001.

AA.VV., Recuerdo de un olvido. María Teresa León en su centenario, Madrid, Sociedad Estatal de Conmemoraciones Culturales, 2003.

AA.VV., Homenaje a María Teresa León en su centenario, ed. de Gonzalo Santonja. Madrid, Sociedad Estatal de Conmemoraciones Culturales, Instituto Castellano y Leonés de la Lengua, Instituto Municipal de Cultura del Ayuntamiento de Burgos y Consejería de Educación y Cultura de la Rioja, 2003. (Actas de las Jornadas "María Teresa León en su centenario").

AA.VV., María Teresa León. Memoria de la hermosura, coordinado por Olga Álvarez de Armas, Madrid, Fundación Autor, 2005.

AA.VV., Escritores, editoriales y revistas del exilio republicano de 1939, ed. de Manuel Aznar Soler, Renacimiento, Gexel, Sevilla, 2006.

ALBERTI, Rafael, "Mi vida con María Teresa León", Homenaje a María Teresa León, Madrid, Universidad Complutense, 1990, pp. 9-11. 
ANA, Marcos, "Testimonio", en AA.VV., Escritores, editoriales y revistas del exilio republicano de 1939, ed. de Manuel Aznar Soler, Renacimiento, Gexel, Sevilla, 2006, pp. 457-461.

ARIAS, Salvador, "Homenaje a María Teresa León", en AA.VV., Escritores, editoriales y revistas del exilio republicano de 1939, ed. de Manuel Aznar Soler, Renacimiento, Gexel, Sevilla, 2006, pp. 425-430.

AZNAR SOLER, Manuel, ed. e introd. a María Teresa León. Teatro (La libertad en el tejado. Sueño y verdad de Francisco de Goya), Sevilla, Renacimiento, 2003.

BLANCO AGUINAGA, Carlos, Julio RODRÍGUEZ PUÉRTOLAS e Iris M. ZAVALA, Historia social de la literatura española (en lengua castellana), III, Madrid, Castalia, 1984.

BLANCO, Alda, "Las voces perdidas: silencio y recuerdo en Memoria de la melancolía de María Teresa León", Anthropos, 125 (octubre de 1991), pp. 45-49.

CAUDET, Francisco, "Vanguardismo, militancia y cultura", en Las cenizas del Fénix. La cultura española de los años 30, Madrid, Ediciones de la Torre, 1993, pp. 17-65.

CIPLIJAUSKAITÉ, Biruté, "Escribir entre dos exilios: las voces femeninas de la generación del 27", en La construcción del yo femenino en la literatura, Cádiz, Universidad de Cádiz, 2004, pp. 97-105.

DOMINGO, Carmen, María Teresa y sus amigos. Biografía política de María Teresa León, Madrid, Fundación Domingo Malagón, Gobierno de España, 2008.

ESTÉBANEZ GIL, Juan Carlos, "La memoria como nexo vital en la obra literaria de María Teresa León", en El exilio Literario español de 1939, Barcelona, Gexel, 1998, Vol. I, pp. 291-299.

ESTÉBANEZ GIL, Juan Carlos, María Teresa León. Escritura, compromiso y memoria, prólogo de Julio Valdeón, colección Beltenebros, Burgos, Fundación Instituto Castellano y Leonés de la Lengua, 2003. 
GONZÁLEZ MARTÍN, Diana, "Imaginar el espacio. Los sueños en la narrativa breve de María Teresa León”, en AA.VV., Escritores, editoriales y revistas del exilio republicano de 1939, ed. de Manuel Aznar Soler, Renacimiento, Gexel, Sevilla, 2006, pp. 431-440.

GRILLO, Rosa María, “La memoria fragmentada (María Teresa León, Dolores Ibárruri, Rosa Chacel, Teresa Pàmies, Federica Montseny, María de la $\bigcirc$ Lejárraga)", en AA.VV., Escritores, editoriales y revistas del exilio republicano de 1939, ed. de Manuel Aznar Soler, Renacimiento, Gexel, Sevilla, 2006, pp. 441-448.

GUILLÉN, Claudio, “María Teresa León y el recuerdo de la fraternidad", en De leyendas y lecciones. Siglos XIX, XX y XXI, Barcelona, Crítica, 2006, pp. 419-429.

LINHARD, Tabea Alexa, "Cuando los melocotones ya son duraznos y la guerra nunca acaba: violencia, género y memoria en un relato de María Teresa León”, en AA.VV., Escritores, editoriales y revistas del exilio republicano de 1939, ed. de Manuel Aznar Soler, Renacimiento, Gexel, Sevilla, 2006, pp. 449-455.

MAINER, José-Carlos, "Las escritoras del 27 (con María Teresa León al fondo)", Homenaje a María Teresa León, Madrid, Universidad Complutense, 1990, pp. 13-39

MARCO, Joaquín, Introducción a Una estrella roja, Madrid, Espasa-Calpe, 1979, pp. 9-23.

MARRAST, Robert, "La obra del exilio de María Teresa León: novela y autobiografía", Homenaje a María Teresa León, Madrid, Universidad Complutense de Madrid, 1990, pp. 75-87.

MARTÍNEZ, Josebe, Exiliadas. Escritoras, Guerra Civil y memoria, Barcelona, Montesinos, 2007.

MONFORTE, Inmaculada, "Una vida en la literatura", aproximación a María Teresa León, Turia, número 13 (febrero de 1990), pp. 60-69. 
MONLEÓN, José, "María Teresa León: revolución y melancolía", en AA.VV., Escritores, editoriales y revistas del exilio republicano de 1939, ed. de Manuel Aznar Soler, Renacimiento, Gexel, Sevilla, 2006, pp. 463-482.

OCHOA, Debra J., "Memory and Exile in María Teresa León's Las peregrinaciones de Teresa (1950)", en Letras Hispanas, Volume 4, Issue 2 (2007), pp. 158-169.

POPE, Randolph D., "La autobiografía del exilio: el ser previamente preocupado de Rafael Alberti y María Teresa León", en El exilio de las Españas de 1939 en las Américas: “¿Adónde fue la canción?», José María Naharro Calderón (Coord.), Barcelona, Anthropos, Memoria rota, 1991, pp. 369-378.

PRADO, Benjamín, "María Teresa León, la mujer inventada", en Los nombres de Antígona, Madrid, Aguilar, 2001, pp. 195-314.

PUERTO, José Luis, "María Teresa León, fábula y poesía", María Teresa León (1903-1988), Madrid, Concejalía de juventud del Ayuntamiento de Madrid, 1990.

RODRIGO, Antonina, "María Teresa León: una mujer en la guerra civil", Vindicación feminista, $n^{\circ} 23$ (1 de mayo de 1978), pp. 36-38.

TORRES NEBRERA, Gregorio, "Introducción biográfica y crítica" a Memoria de la melancolía, Madrid, Castalia, 1998, pp. 7-63.

TORRES NEBRERA, Gregorio, "Introducción" a Fábulas del tiempo amargo y otros relatos, Madrid, Cátedra, 2003, pp. 11-102.

TORRES NEBRERA, Gregorio, La obra literaria de María Teresa León. (Autobiografía, biografía, novelas), Cáceres, Universidad de Extremadura, 1987.

TORRES NEBRERA, Gregorio, Los espacios de la memoria (La obra literaria de María Teresa León), Madrid, De la Torre, 1996. 